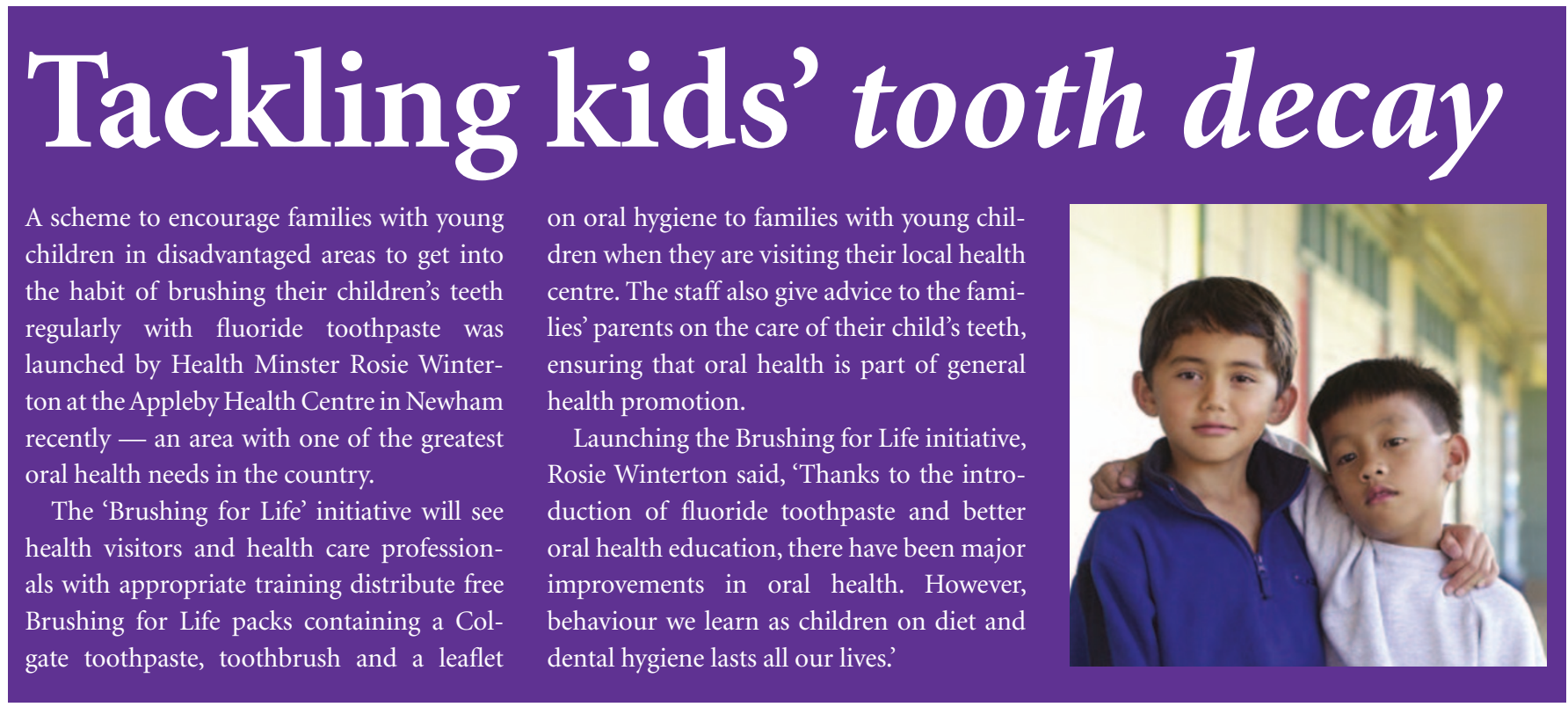

\title{
Positive response to DCP registration
}

Following the opening of the DCP Register on 31 July 2006 the GDC has been delighted with the positive response from dental nurses and technicians. In the first month, the GDC sent out approximately 5,000 application packs in response to requests from DCPs keen to be among the first new registrants.

The GDC's Chief Executive and Registrar, Duncan Rudkin, said that the Council had received an overwhelmingly positive response for application packs and would be sending application packs to those on the voluntary registers from October. 'This is so that we can manage the processing of all applications, to help ensure that applications are turned around as quickly as possible. All dental nurses and technicians on the voluntary registers should receive their application forms by March 2007, he said.
Application packs for dental nurses and technicians and further information about DCP registration are available on the GDC website at http://www.gdc-uk.org. Potential registrants can also request an application pack by emailing their name and address to dcpform@gdc-uk.org or by calling the GDC on 02078873800 .

One of the first registrants to join the new GDC register was Kevin Tinklin, who works as a crown and bridge technician for a laboratory in Nottingham. He warmly welcomes registration for DCPs and remarked, 'At last experienced and qualified technicians have gained recognised status within the profession of dentistry. Now we can justifiably, through our expertise and qualifications, be part of the wider dental team delivering the best care possible for the patient.'

\section{Increased support for practices}

Increased support is being made available for dental practices aiming to achieve a prestigious quality award.

Practices working towards membership of the British Dental Association's Good Practice Scheme will benefit from enhanced telephone support and workshops for practice managers. This support will give applicants more help in developing their portfolio, ensuring they meet the 24 month application window for membership of the Scheme.

A new version of the self-assessment pro- gramme for the Good Practice Scheme will ensure that applying practices are up-todate with the latest requirements, including 10 new requirements drawn from the guidance of organisations including the GDC, the Department of Health, the Health and Safety Executive and the Environment Agency. The programme's model policies and procedures have also been revised, taking into account changes to child protection guidance. For more information telephone $02075634597 / 8$ or email goodpractice@bda.org.

\section{Turn over a}

\section{charitable leaf}

The UK's leading dental charity has announced an exciting opportunity for members of the profession and public to join its Board of Trustees.

The British Dental Health Foundation is a dynamic and proactive organisation, dedicated to promoting the benefits of good oral health to the public. Established for more than 30 years, the Foundation operates a free national Dental Helpline service (0845 0631188$)$ as well as organising National Smile Month and Mouth Cancer Awareness Week - two of the biggest campaigns in the UK calendar. The Foundation requires enthusiastic, committed individuals to govern the organisation and assist in the development of strategic objectives. Dr Nigel Carter, Chief Executive of the Foundation, commented: 'We are fully committed to improving oral health, both in this country and abroad. This is a fantastic and unique opportunity for someone with the necessary drive and passion to help us make as difference.' Trustees are required to meet four times per year and at strategic planning sessions, as necessary. For further information, please contact the British Dental Health Foundation, Smile House, 2 East Union Street, Rugby, Warwickshire, CV22 6AJ. 